\title{
THE EDUCATION QUALITY MEASURING: AMERICAN EXPERIENCE
}

\author{
Iryna Zvarych \\ Department of modern European languages \\ Kyiv National University Trade and Economics \\ 19 Kioto str., Kyiv, Ukraine, 02000 \\ Alla Marushkevych \\ Department of the Pedagogy \\ Kyiv National Taras Shevchenko University \\ 60 Volodymyrska str., Kyiv, Ukraine, 01033
}

\begin{abstract}
The US Higher Education Reform is due to certain processes of competitiveness, market orientation, the tendency to form a single space for education. The American system of Higher Education has integrated the best in the education of other countries and thus helped the country overcome crises, to some extent solve the problems of racial discrimination, unemployment, poverty, improved the situation of women, people with disabilities, national minorities. The historical events, socio-economic transformations, aspiration to be a leader in the world market respectively have influenced the development of Higher Education. Due to reforms in American society, education has become more open, various, versatile. The Americans highly value the Higher Education and believe that education is necessary for a conscious political life, the functioning of a democratic government, the development of economic and political international relations. The American education serving the dynamic and global economy is effective and capable of developing in the conditions of limited public resources.

This article focuses on the measurement of education quality and accreditation of Higher Learning Institutions in the USA; the analysis of educational activities of American universities; the coverage of accreditation and education performance of Higher Learning Institutions in the United States; these indicators usage in the process of education quality assessing in American universities; the essence disclosure of measurement the education quality with helping "added value" on the basis by American scientists research; the borrowing American experience into the Higher Learning Institutions in Ukraine.
\end{abstract}

Keywords: Higher Learning Institution, accreditation, measurement, evaluation, teachers and lecturers, education quality and education service, reform, society, subject, progress, modern development, level.

\section{Introduction}

The continuous science development is strongly influenced by changes in the area of education in Ukraine. There is a need to take into account the differences between the quality of knowledge received by students and the level of needs in the labor market. There are new contradictions between the person requirements of high-tech society and the level of professional training. The link between education and production as a component of scientific and technological progress is not sufficiently effective. This calls for the new technologies development of specialists' high-quality training who have the capability of influence into the modern economy development and social relations, social and cultural spheres of Ukrainian society life, which puts forward a number of vital tasks before the Higher Education Institution concerning the introduction of new educational standards, development of the new education quality criteria different from the previous ones but oriented to the indicators of those world countries which have high achievements in the area of education.

The guidelines for this case are the Act of Ukraine "On Education" (2017), the Act of Ukraine "On Higher Education" (2014), "National Strategy for the Education Development of Ukraine until 2021" (2013), the Concept of Children's National Patriotic Education and the Youth Program (2015), the Program of Students' Patriotic Education in Ukrainian Education Establishments (2013), the National Qualifications Framework (2011), "Approaches to Ensuring the Priority Education Development in Ukraine” (2010), "Research University “(2010) and others. The Higher Education Reforms, conducting research and teaching activities in Education Institutions by scien- 
tific and pedagogical workers and students, and gaining significant results in the area of methods, techniques, technologies, the experience of other countries is important.

Multidimensional international experience, in particular the education quality in the USA Higher Education Institutions, which contributes to the national pedagogic enrichment and involves the education development study in the wide context of political, economic, social and cultural factors in the interconnection and interdependence of regional and national trends, are considered by Ukrainian and American researchers.

\section{Aim of research}

To focus on the education quality measurement and accreditation of Higher Learning Institutions in the USA and Ukraine.

\section{The comparative analysis of the education quality measurement in Higher Learning Insti- tutions of the USA and Ukraine}

The quality education evaluation of Higher Education Institutions in the United States depends on the certain indicators of measurement, in particular on accreditation of Higher Education Institutions and their education activity.

The accreditation of Higher Education Institutions of the USA is carried out by: accreditation organizations, accreditation organizations determination, representatives of the federal government, and state government. Independent and qualified experts check the educational activities of a particular university, paying attention to the implementation of the approved program, as in the United States, not only the Higher Education Institution accreditation, but also the accreditation of the professional higher education program.

Judith S. Eaton, president of the Council for Higher Education Accreditation (CHEA), underlines that USA accreditation organizations are legitimizing themselves from colleges, universities and programs that are accredited, and not from the government [1]. It would be better to emphasize that the Council for the Accreditation of Higher Education (CHEA) is a private, national organization, but non-state. It covers more than 300 Higher Education Institutions and it is headed by a collegium of university representatives.

The are 60 accreditation organizations in the United States which are recognized by the Accreditation Board in the Higher Education System, because it is this United States Department of Education (USDE) that controls the activities of the accreditation organization. The US Department of Education (USDE) is an organization of the federal government that, within its authority, examines the capacity of accreditation organizations to ensure the quality of the education process in Higher Education Institutions, on the basis of which the Higher Learning Institutions are financed from the state budget. That's why the USA accreditation organizations consider their activity as providing services, rather than regulating education activities, since they largely carry out education functions, not controlling. The main objective of the accreditation organizations is to help Higher Education Institutions to develop their professional program, promote its implementation, and not prescribe requirements and establish standards. The United States Accreditation Organizations provide some advice to representatives of Higher Education Institutions, evaluate the education activities of universities and engage in analytical work. That's why the USA accreditation organizations serve not only the state Higher Education Institutes, but also 125 other countries of the world [2].

The indicators of the Higher Education Accreditation are determined by certain criteria recognized by the regional authorities for accreditation of Higher Education. Accreditation indicators provide the opportunity for universities to receive scholarships from the state budget at various levels and funding from both state and commercial organizations, as well as graduates' diplomas recognize by the state employers. Almost all US Higher Education Institutions, including colleges, are accredited, despite the fact that this is the voluntary affair. The universities of particular specialty are not involved into the process of accreditation.

The indicators of the education activity of Higher Education include indicators developed and established by the states ruling circles where the university is located, or by the Higher Educa- 
tion Institutions administration. Education performance indicators of Higher Education Institutions are used for: comprising education activities of state universities, funding Higher Education Institute from different sources, reporting to the ruling circles to improve the education process quality, the teachers' professional activities, in particular teaching subjects and assessing the knowledge quality as teachers and the students as well.

American researcher R. Birnbaum highlights that higher education quality in the United States depends on the measurement of meritocratic indicators, social, individual, in particular, meritocratic are based on the conformity of education with professional and scientific norms of teachers' professional activity, social - meeting the needs of society, individual - development of the student knowledge level [3].

To the significant indicators of education activity in US Higher Education Institutions are included: the percentage of graduation/dropout of students, the percentage of graduates who have completed the certain Higher Education Institution for 6 years, the percentage of professional employment, the access level to Higher Education (the percentage of application enrollment for all ages, race), financial expenses (cost of training, financial assistance to students), the quality level of teachers' professional activity, in particular, subject knowledge and their ability to teach students, the availability of a science degree, and amount of published articles [4, p. 12].

All these indicators are quantitative, which in some way characterize the education services level, and indicators of subject awareness and the ability to teach indicate quality. Thus, indicators of quantity and quality characterize the education quality, in particular, the provision of education services at Higher Education Institutions. If you can count the number of indicators and determine the rating, so the quality indicators require a professional approach to their determination. Also, for the quality marks, it can be given the right score as well and they can be counted too. However, such indicators will have signs of formalities and will characterize the education quality in relation to the provision of education services, in particular. But, if we take into account the total number of indicators that cover the number of scientific achievements and determine their quality, then one can try to characterize the education quality, including the education services provision in more detail and professionally. Thus, we can note that education in Higher Education Institutions needs to be measured.

The education quality measuring at US Higher Education Institutions is a complex process that involves making decisions on the tasks format, procedures for testing both as students and teachers as well, attracting additional material from the subjects and pedagogy to the group, building a portfolio, using the latest computer technologies. In countries with a centralized education system, there are significant differences in the goals definition of the measurement system and decision-making in determining the quality level of professional activity, in particular pedagogical competence.

In countries with a decentralized education system, in the United States particularly, determining the student knowledge level and assessing the teaching professional activity of teachers is carried out by individual states, counties that develop certain requirements and standards. If the assessment of the student knowledge level is carried out by the teachers, then, before determining the quality level of teachers' professional activity, engage experts who think over the whole process thoroughly, in particular regarding data collection, scoring, analysis of the evaluation process and the confidence formation in the feasibility of the results. The use of additional training materials or technical equipment will increase the validity of the measurement tools, but this may reduce their reliability as the standardization of the tests offered for diagnosis is complicated. Tests on the measurement of the teachers' professional activity, in particular pedagogic competence, include tasks that involve a detailed response, as well as a complex evaluation system. In the process of measuring quantitative and qualitative indicators of teachers' professional activity use multi-choice tests, where someone can choose one answer to the task out of several proposed. However, multiple-choice tests have certain disadvantages, because they do not reflect a lot of practical tasks, and teachers choose one of the suggested answers instead of offering their own. Therefore, multi-choice tests are offered, with tasks that include interpretation questions, and open responses. Such task formats include written responses, drawings, diagrams, charts, graphs or even the development of 
some models. The advantage of these tasks is that they allow you to measure much more results than just the task of multiple choice.

In the United States, the teachers' portfolio is included to the process of assessment of the teachers' profession activity, this portfolio is evaluated in the process of measuring the educational activities of Higher Education Institute as well. The essence of this assessment process is that the teachers form the portfolio themselves and get the best samples of video footage of training lessons and additional training materials. The formed teachers' portfolios are transferred to a centralized institution, where the teachers' professional activity, their pedagogical competence, and skills are evaluated. Thanks to the portfolio, teachers have the opportunity to demonstrate their best achievements in the process of teaching the necessary subjects. The experts observe and develop the additional tasks for teachers which they can use during the education process, determine the points for each type of professional activity and measure all of them, in particular, they evaluate the lecturers' ability to represent the teaching material, the teachers' behave in the students' audience and the ability to keep the students' attention, teachers' skills, their kindness, establishing a good group moral climate, pedagogic competence, etc. [5].

The computer technologies are involved to the process of measuring the teachers' professional activities of United States university, that allow to combine the tools measuring with interactive systems, where teachers can record and fix their answers of the evaluation process. Due to the computers technologies, the evaluation of teachers' professional activity is carried out at the moment when they introduce their answers to the proposed tasks. Computer technologies do not allow to determine the quality of teachers' responses, but allow to capture approaches effectively to the task of measuring professional activities in order to evaluate responses and pedagogical competence properly.

An American researcher A. W. Astin suggests to evaluate the education quality at US universities by means of measuring "added value" to compare the status of educational activities before and after the completion of the learning process, rather than national standards. He proposes to measure the intellectual development of students in the first year, to follow their level of development throughout the period of study at universities, to compare it at the end of the study, and to determine the quality level of both as profession competence and the mastered competence during the period of gaining the knowledge at university [6, p. 25]. According to A. W. Astin, "value added" highlights the changes in the students' intellectual development from the beginning of mastering the professional program and to its completion. The scientist points out that the perfection of measuring education through "added value" lies in the ability of Higher Education Institutions to influence the students' intellectual and professional development and to change their future professionals' lives for better.

The qualitative education is in those Higher Learning Universities where they can influence to the intellectual, professional, personal development of students during the program's mastering at a Higher Education Institution most of all. We share the opinion of the American scholar that the "added value" approach points somehow to the changes of students' intellectual and professional development, the level of accumulated knowledge for the further work of future professionals, but to determine the education quality due to ability of influence to the students' development is inappropriate, as the person develops continuously and independently from Higher Learning Institution. However, the education activity at Higher Education Institutions may contribute the accumulation of students' professional knowledge in some way and increase their level quality, develop their skills for future activities.

An American Researcher D. M. Green considers that a high-quality Higher Learning Institution is that where the education activities in achieving goals are carried out clearly [7, p. 15].

Analyzing the education quality condition in Ukraine, we must bear in mind that the modernization of Ukrainian society depends on the young generation education level, which is capable of competing in the labor market with strict selection. The young population education level of the country is a significant indicator that influences to the higher education conditions and its integration into the world education space. Young people want to become the high-level specialists who are capable for creative activity in acquiring knowledge which assists in professional career. 
Today, the most competitive are people with Higher Education, because only they are most often charged with the requirements of those employers who seek to invite from among the candidates for the available vacancies the most capable to provide the relevant work area. For the better understanding of these processes essence, we should must recall the meaning of "optimization" concepts, which comes from "... lat. optimus - the best" and means "the process of providing any of the most profitable characteristics, relations... " [8, p. 483] and "modernization", which has the French origin "modernization-updating", and is to be interpreted as "... updating, improving, providing any modern look, processing in accordance with modern requirements..." [8, p. 443]. They are often heard and spoken with youth communication, as well as "integration" concept, that can be translated from "lat. integratio - replenishment, restoration" and in the explanation "... combining of any individual parts in the whole" [8, p. 286-287]. Nowadays, the focus on the integration of countries education systems that combine their efforts to create a single education space, envisages the actives enrichment of Higher Learning Institutions. This is manifested in the introduction of new education technologies for the competent specialists training in a particular industry, the students' formation of professionally meaningful and socially necessary personal qualities, ability to independent, creative activity.

Assessing the specialists' training quality at the Higher Learning Institutions (universities) of Ukraine, the application of the most advanced technologies, methods, techniques, means for the qualitative provision to gain the students' knowledge, the development of their respective abilities and skills for future professional activity is taken into account by the lecturers; pay attention to the lecturers' competence, which manifests itself in the impeccable performance of his/her duties, sufficient knowledge possession for the teaching subject, experience in a particular field of activity; his/her professional competence, which consists in personal capabilities based on the ability to ensure the process goals, to transfer the knowledge for students independently and qualitatively, due to the teaching theory possession and practice implementation during classroom work with youth and etc. In the teachers' professional competence are expected not only his/her professional knowledge, but also professional skills, professional ability, professional positions and installations, individual features, etc. All of them characterize him/her as a specialist with an individual work style, only with his/her unique features that are based on the age-old awareness peculiarities of young people and their ability to master the education material, the creative use of didactic knowledge which are formed on the levels of methodology, theory and technology.

Based on the foregoing, we can state: the high mark of teachers' activity has the highly qualified lecturers who aware the fact that education is one of the locomotive power of the country's development and they try to fill its content with innovations: innovative methods and methods of pedagogic actions based on modeling, organizing non-standard lectures-practices and seminars; reformatting classroom, group and additional training; developing a new system for assessing knowledge; involving the computer and multimedia technologies, educational-and methodical outputs of the new generation, etc.

Besides, the teacher's ability to apply effective teaching tools is highly appreciated: audio-, video-, electronic media (programmable teaching books, scientific journals, dictionaries, lecture texts, virtual laboratory work, online coaching, testing, etc.), that, in combination with traditional teaching methods has significant results, that can help students to acquire new knowledge as in and as outside the classrooms. The very important fact of the teacher's work is the electronic creation and methodology education complexes, that ensures the implementation functions such as: information, structure systematizing, motivational-and-stimulating, interactive didactic and also the consolidation function control and self-control.

The education technologies as means of knowledge that can be used in any subject studying are important in the youth teaching process of vocational and pedagogic preparation in Higher Learning Institutions. The education technologies are tangent to the process of designing student knowledge, which is related to the information they have previously learned and their beliefs. Under the condition of distance learning, the technology of an online seminar is effective, during which comparative tables, presentations, videos, etc. are shown. Such a seminar has the most im- 
portant feature - interactivity, which provides simulation of the trencher's functions, a listener, who will cooperate in a conduct scenario [9, p. 443].

However, as experience shows that the student knowledge level at Higher Education Institution is characterized by a number of significant disadvantages associated with the incomplete compliance of the acquired knowledge, skills and abilities with the specifics of future professional activities and the requirements for the personality of a modern specialist.

The gained theory knowledge by young people is used in particular situations, but not in everyday practical activity in the process of solving important tasks. Due to this, the very important vision comes that the assimilation of a large amount of theory material without communication and practice has no sense. Awareness of this fact by students reduces their motivation and interest in learning [10, p. 44]. If a student imagines badly why he/she studies a huge amount of non-practical tasks of the theory material, then this does not significantly change his/her desire to be well prepared for professional activity. The need is quite high for training highly skilled personnel who are capable to provide all high-quality spheres of society life in Ukraine. Having the great experience of students' training, lecturers are interested particularly in the specialists' achievements from different countries in the field of providing skilled personnel of the spheres of education, scientific, culture, industry and artistic. They note that the most influence point in this process is education, which "... can provide international competitiveness by combining the three components of the development spiral such as: education, science and innovation" [11, p. 8]. Due to the fact that in most Higher Education Institutions in Ukraine specialists' training and retraining is being carried out, "... the components of the" knowledge triangle "- education, science and innovations are divided by this time" $[11$, p. 8)]. The most suitable structures for transformations, within education, scientific and innovative projects are implemented, have become Research Universities with well thought-out professional training of young people.

The process of preparing competitive specialists in the modern labor market is accompanied by substantial changes, the development of modern information and telecommunication support, overcoming the obstacles in knowing foreign experience through the use of various information resources. In this context, it is impossible to ignore the important trends of Higher Education, among which we distinguish "the study of national strategies development, reports", "trends of development and perspective directions of further research" [11, p. 9)]. The analysis of “... education policy, world, European and national normative-legal documents bases; indicators of the development of society, available and accessible regional and national statistics data on education for detailed analysis, etc." [12, p. 63]. This is necessary in order to understand the essence of the specialist's quality training, the achieved level in this field in the past, and to define the tasks for the future. As of today, one of the main tasks of Higher Education Institutes is "... not only the professional training of bachelors, postgraduates and master's degree, but also the formation of their research skills" [11, p. 9].

Ukrainian scientists believe that in order to intensify research work at Higher Education Institutions, it is necessary to foresee in the specialists' training curricula the methodology study for scientific research, the methods for analyzing scientific sources, the technology of writing and further development of the scientific research, the obtained synthesis of scientific results [9]. Another important point is the personal interest of the student in solving scientific problems, carrying out joint research with lecturers, increasing the students' work proportion in the state budget execution, inter-governmental projects and international projects, as well as giving teachers time for leadership the scientific circles, problem groups, preparation for competitions, contests, research publications according to the individual plans and curricular [13, p. 32-40].

The important innovation component is research areas as an integral part of the science development, education and businesses as well.

Assessing the students' research skills is important to take into account the orientation of professional training to develop their ability for applying in practice general and specific scientific methods of cognition, using the innovative potential of teaching and methodology complex, the mastering level their research skills in the optimal combination process of traditional and innovative learning. 
Ensuring the fair evaluation results is possible in the new system of development the assessment knowledge level with involved computers, multimedia technologies, and etc.

The Act of Ukraine "On Higher Education" emphasizes that competence is a dynamic combination of knowledge, skills and practices skills, ways of thinking, professional, ideological and civic qualities, moral and ethical values, which determines the person's ability to carry out professional and further education activities successfully and is the result of studying at a certain level of Higher Education [14]. The level of teachers' professional competence of Higher Education Institutions in Ukraine is evaluated in view of the labor market needs in the highly skilled specialists who are trained in these Institutions. Such an assessment is one of the criteria for improving the teaching subjects' quality. The factors that enhance the competitiveness of Higher Education Institutions include their certification, which can't be carried out without highly qualified lecturers with science degrees of doctors and Ph.G. Diagnosing their professional competence level belongs to the tasks of improving the teaching quality in the process of studying the subject.

Assessing the teacher's professional competence level, we focus on his/her abilities very often, which develop in the process of fulfilling his/her tasks, although we realize that: every person has special provision of their professional duties' tricks. The teacher's ability of Higher Education is one of the conditions for ensuring that he/she has an appropriate teaching level in the Higher Learning Institutes. Nevertheless, the Lecturers must have the readiness for teaching work, the ability to carry it out. For the development of such ability pre-training, emotional adjustment, the availability of practical data, etc are required.

We must also take into account the fact, that in the professional activity of the teacher's competence of Higher Education means: the mastering of the necessary knowledge, professional reproduction of the most important for them at the lectures, skillfully diagnosing their mastering level by students, performing other actions that enable them to obtain qualitative results and achieve their goal activities. Professional activity includes the specialist activity directed to the achievement of the result, and professional competence, respectively, is the culture and speech style and value orientation, the attitude towards other subjects, to him/herself, and others like that.

The teachers' pedagogical activity includes some components of education, organization, methodology, scientific, culture and others. It is characterized by its pedagogic skill, scientific, creativity, development quality of the proposed methods, attitude to the education process, colleagues, students, etc. Pedagogic activity is a complex combination of all his/her characteristics, which are manifested in the process of providing his/her education and cognitive activities and are based on high spiritual, moral and democratic principles of students' education and upbringing.

Describing the personal pedagogic activity, we pay attention to his/her productivity. It's important to know about the teacher's professional readiness, which testifies his/her adaptation level to the existing working conditions, includes the components of motivation, orientation, operation and others.

The teachers' professional competence requires the deep knowledge of theory and methodology and also the corresponding level of education and professional skills.

Having paid attention to the American experience, we underline that in our country, the assessment of the teachers' professional competence level is provided by the education staff, experts, students, the administration of Higher Learning Institutions. In the assessment process some main features are taken into account in the first place, such as: the teacher's awareness with students' group stratum whom he/she teaches; ability to plan the education process; ability to logically and consistently teach education material, it is accessible to inform students about its content; the ability to apply the latest technology in the professional content of the education process; the possession f scientific information proposed by young people and the need of awareness to support student judgments and create a friendly atmosphere for their interest in the process of studying; objectivity of assessing the students' qualitative knowledge level. It should focus on identifying the level of teacher compliance with the practical activities of the most important science principles (the organized education process with modern technology with the newest scientific information); sequence (concentration of each subsequent further topic study based on the assimilation of the previous one); systematic (teaching of educational material taking into account the normative base, existing standards regarding to the teaching content, ongoing control of students' knowledge acquisition, 
etc.); practical orientation (correspondence of the education material contents to the needs of future specialists in ensuring their practical activity).

The assessment teachers' professional competence level of Higher Learning Institutions should be based on standards which are the established requirements for checking the results of the study subject program implementation, which can determine the real level of their education, methodology, scientific and research activities. These standards should relate to the teachers' work discipline, their ethics of relationships with colleagues and students, and community activities. In addition, the standards for teachers' assessing the professional competence focus on the complex implementation of work curricula.

The main attention should be paid to the traditional methods for assessing the teachers' professional competence level in Higher Learning Institutions. The most common among them are testing methods, questionnaires, surveys, and diagnostics. Testing, as one of the well-known methods for assessing the teacher's professional competence level, is distinguished by the availability, the ability to determine his/her subject knowledge quality and the ability to teach this subject, the teacher's readiness degree for the education process conduct. An important question in assessing the teachers' professional competence level is the students' questioning. It is used to collect the required material using specially designed questionnaires. In these questionnaires students present both as grades and as marks of the teachers' professional competence. The questionnaire (oral or written) helps to identify the satisfaction level or not perception by the students' manner in which a particular specialist is taught, structuring and providing scientific and informational support for students and controlling their knowledge, skills and abilities, etc. Diagnosis involves one or another result of mastering young people with the subject knowledge, which is provided by a certain representative of the teaching staff at Higher Learning Institution.

The main criteria for teachers' quality assessing work with students in the process of subject teaching is the lecture content, characterized by a scientific level, compliance with the program and curriculum, the modern achievements in the field of practice, etc.; its methodology level, based on the application methods of activating cognitive activity of students in the process of studying, the requirements of related courses; structure (introduction with clear theme formations and purpose setting, main idea, content, plan availability, literature list, tasks for independent work, and result); the lecturer's skill (lecture possession knowledge degree, tactful attitude towards students, restraint in discussions and answers to their questions, ability to relieve tension and fatigue in the audience), etc.

Assessing the teaching competence level of university teachers, it is worth paying attention to the degree of their objectivity in the process of evaluation the studding students' achievements. This will help to determine the teachers' knowledge level regarding compliance with established norms, criteria for qualitative evaluation. Objectivity in the process of assessing the students' knowledge quality points to the teacher's training level and significantly affects the ranking of his/her activities.

The assessment of teacher's competence level is usually provided by experts, administration of Higher Education Institutions, students, etc. and can be carried out according to the following criteria: teachers' knowledge with students' group; ability to plan the educational process; ability to logically and consistently teach education material, it is accessible to inform students about its content; the ability to apply the modern technology in the professional provision of the learning process; ownership of the proposed youth by scientific information; awareness of the need to support student judgments and to create a friendly atmosphere for their interest in the learning process; the assessment of students' knowledge quality objectivity, etc. Assessment of the teachers' pedagogical competence level of Higher Learning Institutions should be based on the established requirements standards for checking the results of the implementation of subjects programs, by which one can determine the real level of their education, scientific and methodological, scientific research activity (these standards should also relate to the teachers' work discipline, the ethics of relationships with colleagues and students, public activities). It is necessary in view of the labor market need in highly skilled specialists trained in Higher Education Institutions and is one of the criteria for improving the quality of teaching disciplines, and, in general, for the successful reformation of the education area.

In Ukraine, in accordance to the Article 18 of the Ukrainian Act "On Higher Education" (2014), the powers of the National Agency for the Quality Assurance of Higher Education are 
indicated. It states that its forms the requirements for the system of quality assurance in Higher Education, develops the provision for accreditation of education programs and submits it for approval to the central executive body in the field of education and science; analyzes the education activities quality of Higher Learning Institutions; conducts a licensing examination, prepares an expert opinion on the possibility of issuing a license for the education activities conduct; formulate the proposals of Higher Education Institutes (scientific institutions), proposals, including the purpose of introducing inter-subjective training, on the list of specialties for which higher education graduates are trained at the appropriate levels of Higher Education, and submit it to the central executive authority in the field of education and science; forms a unified database of Higher Education Institutions that specialize in the training of higher education graduates at each level of Higher Education; carries out the accreditation of education programs for the applicants training for Higher Education; establishes criteria of quality assessing the education activities, including scientific achievements, Higher Education Institutions of Ukraine, which can determine the ratings of Higher Education Institutions of Ukraine; develops the requirements for persons' scientific qualification level who acquire scientific degrees, develops the procedure for their award by specialized scientists councils of Higher Education Institutions (science institutions) and submits it for approval to the central executive body in the field of education and science, etc.

The National Agency for the Quality Assurance of Higher Education invites international experts - professors from leading foreign Higher Learning Institutions and/or experts from institutions providing higher education quality in other countries to participate in their activities [14].

Article 25 of the Ukraine Act "On Education" (2017) specifies the main positions regarding the accreditation of education programs. They are as follows.

1. The Higher Learning Institution that wishes to accredit the education program submits a written application to the National Agency for the Quality of Higher Education and documents confirming its education activity accordance with the standard of Higher Education in the corresponding specialty.

2. Within two months from the date of application submission, the National Agency for the Quality Assurance of Higher Education, on the basis of the accreditation examination results, takes the decision on accreditation or refusal to accredit the relevant education program. The decision on the accreditation of the education program is made on the basis of the expert opinion of the relevant sector expert council, which represents the chairman of this expert council.

3. Within three working days from the decision day on accreditation of the education program is made, the National Agency for the Quality Assurance of Higher Education issues the corresponding certificate to the Higher Education Institution [14].

\section{Research results and discussion}

The comparative analyse of Higher Learning Institutions accreditation has shown two different reproaches to the measurement system. The accreditation of Higher Learning Institutions in the USA is the proses where the Higher Education Institutes have the great desire to take part in the process of measurement, because they will have the additional financial support of Government and the separate state as well. That's why they try to have innovations in the education system and teachers ' assessment too. To compare with Ukrainian system of Higher Learning Institutions accreditation, so they have the state financial support just a little. That's why they have small interests to include the newest education innovations and the teachers' assessment in the education process, because they try to find the sponsors of additional education support firstly and then for education innovations, teachers' assessment and accreditation. Some Ukrainian scientists $(4,5)$ tried to show the methods of accreditation and teachers' assessment, but they didn't highlight the reasons why the Ukrainian Higher Learnings did have small desire to take part in accreditation.

The main study results and conclusions were discussed and made public in speeches, science reports at the conferences in particular, international: International scientific and practical conference "Service economy in the conditions of global competition: legal and institutional dimensions" (Kyiv, 2017), IX International science-and-practical conference "Pedagogy of Higher School: 
Methodology, Theory, Technology" (Kamyanets-Podilsk, 2015); Science-and-practical conference "Pedagogy of Higher School: Methodology, Theory, Technology" (Pereyaslav-Khmelnitsky, 2011); "Pedagogy of Higher School: Methodology, Theory, Technology" (Cherkasy, 2012); All-Ukrainian: "Ethnic Dimensions of the Universe: Language, Literature, Culture" (Kiev, 2010); "Ukraine and Germany: Language, Culture, Education" (Kryviy Rih, 2014); Interuniversity: "Teaching a Foreign Language at Higher Learning Institutions" (Kyiv, 2008);

\section{Conclusion}

1. The education quality measurement it is the necessary and disable process that should be directed to the improving of education activities and providing education services in order to become better the education quality at Higher Learning Institutions of Ukraine.

2. Accreditation in Ukrainian Education Institutions should become a community value and be used more widely to determine the rating among other universities, which in particular will have a certain impact on the increased funding of Higher Education Institutions from both as the state and as commercial structures.

3. The accreditation of Higher Learning Institutions in Ukraine won't fulfill the function of incomprehensible assessment, but will be desirable in every Learning Institution, because in particular the Higher Learning Institutions will have the initiative to conduct such the education quality measurement procedure in order to have close interaction with the government and additional financial support that will affect the service education quality and education services provision at a Higher Education Institution.

\section{References}

[1] Eaton, S. (2015). Jud. Accreditation. An overview of US Accreditation. Council for Higher Education Accreditation (CHEA). Washington. Available at: https://www.chea.org/userfiles/uploads/Overview\%20of\%20US\%20Accreditation\%202015.pdf

[2] Council for Higher Education Accreditation (CHEA). Washigton. Data Views 12.06.2017. http:// www.chea.org/

[3] Birnbaum, R. (1994). The Quality Cube: How College Presidents Assess Excellence. Journal of Tertiary Education Administration, 16 (1), 69-79. doi: 10.1080/1036970940160106

[4] Kalinina, O. G. (2015). System of education quality management at Higher Educational Institutions of the United States. Luhansk: Luhansk National Taras Shevchenko Pedagogical University, 21.

[5] Zvarych, I. M. (2014). Teachers' professional activity evaluation at Higher Learning Institutions of the USA (the second half of the XX-th - beginning of the XXI-st century). Kyiv: Phenix, 344.

[6] Astin, A. W. (1985). Achieving Educational Excellence: A Critical Assessment of Priorities and Practices in Higher Education. San Francisco: Jossey-Bass, 288.

[7] Green, D. M. (1994). Society for Research into Higher Education: What is quality in higher education? London, 132.

[8] Melnychuk, O. S. (1977). Dictionary of foreign words. Kyiv: Main Office of Ukrainian Soviet. Encyclopedia, 776.

[9] Saukh, P. Yu. (2011). Innovations of higher education: problems, experience, perspectives. Zhytomyr: Publishing house ZSU named after I. Franko, 443.

[10] Dokuchaeva, V. V. (2007). Theoretical and methodological principles of designing innovative pedagogical systems. Luhansk: Luhansk National Taras Shevchenko Pedagogical University, 44.

[11] Melnychuk, D. O. (2012). The education process organization of research type Universities. Kyiv: Publishing Center of NUBiP, 612.

[12] Terentyeva, N. O. (2016). Intersubjective as the basis of a new knowledgeable product in the information society. Pedagogics and Psychology: Bulletin of the National Academy of Sciences of Ukraine, $1(90), 59-65$.

[13] Yaroshenko, O. G., Skyba, Yu. A. (2016). Practice state of student research at universities. Pedagogics and Psychology: Bulletin of the National Academy of Sciences of Ukraine, 1 (90), 32-40.

[14] On Higher Education (2014). Verkhovna Rada of Ukraine, No. 1556-VII. Available at: http:// zakon5.rada.gov.ua/laws/show/1556-18 